\title{
Pesticide Applicator CEU Opportunities via the UF/IFAS Pesticide Information Offices On-Line Interactive Tutorials 1
}

Fred Fishel and Jason Ferrell ${ }^{2}$

\section{Introduction}

Certified pesticide applicators in Florida are required by law to accumulate generally 4 to 16 continuing education units (CEUs) per license cycle. License cycles vary, but range from one to four years, depending upon type of license and specific categories held by the applicator. Traditionally, applicators have earned their CEU requirements by attending educational programs sponsored by cooperative extension, commodity associations, and private industry. Often applicators are faced with CEU deficits as their license cycle nears expiration. A recent survey of applicators indicated that a large majority are willing to travel to regional or at least adjacent counties for CEU programs. However, only a few have unlimited travel ability and budgets.

\section{Development of On-Line, Interactive Tutorials}

Because of the existing situation, the UF/IFAS Pesticide Information Office initiated a project in
2006 to develop on-line, interactive tutorials for pesticide applicator CEU credit. The purpose of the project was to offer applicators a venue where they could obtain CEU credit without travel for a reasonable expense. Authors of each interactive tutorial develop their presentations using Power Point $^{\circledR}$ as the visual software media. The Power Point ${ }^{\circledR}$ file is then embedded into the audio software, Articulate $^{\circledR}$. The platform allows for the author to use recorded voice narration into each individual slide. Because each individual slide has its own narration file, slides can be rearranged at any future time. Another advantage is that an individual slide can be edited without re-narrating the entire presentation. Upon completion of a presentation, Articulate ${ }^{\circledR}$ is then published as a Flash Macromedia ${ }^{\circledR}$ file. Articulate ${ }^{\circledR}$ will also interface with other software, such as allowing video incorporation. To enhance user interactivity and learning, quizzes are incorporated into each presentation using the software, Articulate Quizmaker ${ }^{\circledR}$. The present software contains 21 options for quiz formats, including true/false, multiple choice, Likert scale,

1. This document is PI-144, one of a series of the Pesticide Information Office, Florida Cooperative Extension Service, Institute of Food and Agricultural Sciences, University of Florida. Published January 2007. Visit the EDIS Web Site at http://edis.ifas.ufl.edu.

2. Frederick Fishel, associate professor, Agronomy Department, and director, Pesticide Information Office; Jason Ferrell, associate professor, Agronomy Department; Florida Cooperative Extension Service, Institute of Food and Agricultural Sciences, University of Florida, Gainesville, FL 32611.

The use of trade names in this publication is solely for the purpose of providing specific information. UF/IFAS does not guarantee or warranty the products named, and references to them in this publication does not signify our approval to the exclusion of other products of suitable composition.

The Institute of Food and Agricultural Sciences (IFAS) is an Equal Opportunity Institution authorized to provide research, educational information and other services only to individuals and institutions that function with non-discrimination with respect to race, creed, color, religion, age, disability, sex, sexual orientation, marital status, national origin, political opinions or affiliations. U.S. Department of Agriculture, Cooperative Extension Service, University of Florida, IFAS, Florida A. \& M. University Cooperative Extension Program, and Boards of County Commissioners Cooperating. Larry Arrington, Dean 
matching, and others. Incorrect answers entered by the user can elicit no response, the correct answer, a response that the answer is incorrect, or transport the user directly back to the relevant information within the presentation.

\section{Application of the On-Line, Interactive Tutorials}

Upon completion of a presentation, the author submits the file to the Florida Department of Agriculture and Consumer Services (FDACS) for CEU credit approval. If approval is granted, FDACS assigns the allowable number of CEUs and the applicator categories approved for use. Each tutorial is posted on-line by the IFAS Extension Bookstore as a for-sale publication at http://www.ifasbooks.ufl.edu/merchant2/. Just as with traditional book and software sales, each tutorial is advertised with a brief written description so that the potential user has knowledge of the approved categories and CEU credit (Figure 1). At the present, a user must call by telephone to purchase tutorials at 1-800-226-1764. Following purchase of a tutorial, the user is then allowed to proceed into the program (Figures 2, 3 and 4). As the user follows along in the tutorial, the interactive quizzes are interjected (Figure 5). Prior to advancing, the user must correctly answer the question presented. At no place in each tutorial is the user allowed to advance without at least playing the presented slide once. A final quiz is placed at the conclusion of selected tutorials, which the user must complete as previously stated. Most of the tutorials have a written text script which may be viewed simultaneously with the video content. Following successful completion of a tutorial, the user is presented with the FDACS credit approval form as with attending a traditional program. The first phase of this project had 13 available tutorials, each at a cost of $\$ 20$, and each approved for one CEU. Various FDACS agricultural categories are approved depending upon individual tutorial.

\section{Conclusions}

The current software technology has potential for uses in various distance educational venues. Conducting traditional face-to-face classroom teaching requires participant travel and expense.

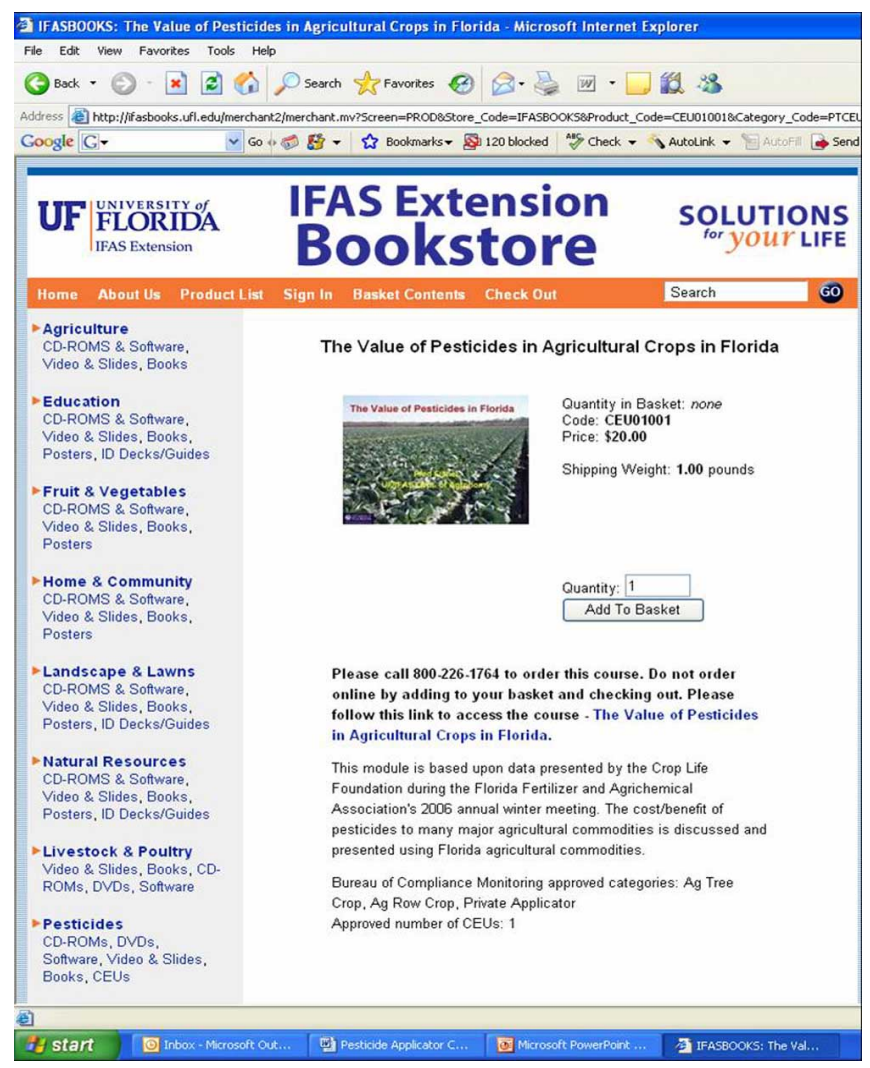

Figure 1. Example of a tutorial advertised through the IFAS Extension Bookstore.

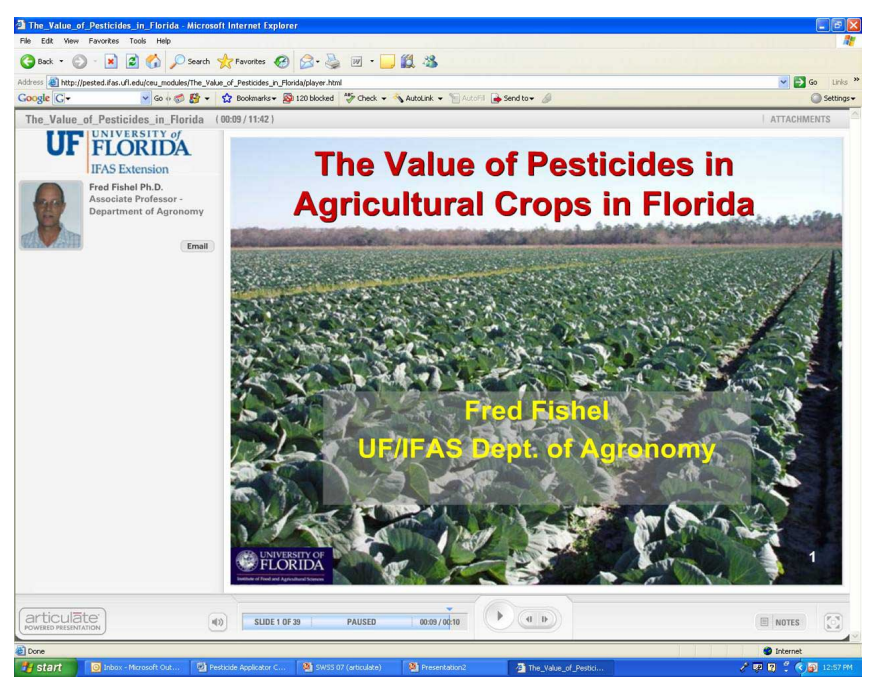

Figure 2. Example of tutorial title slide.

Flexibility is offered to both the instructor and audience, in that tutorials can be prepared at the instructors will, and taken at the pace and in the comfort of the learners chosen location, provided there is computer and internet access. 


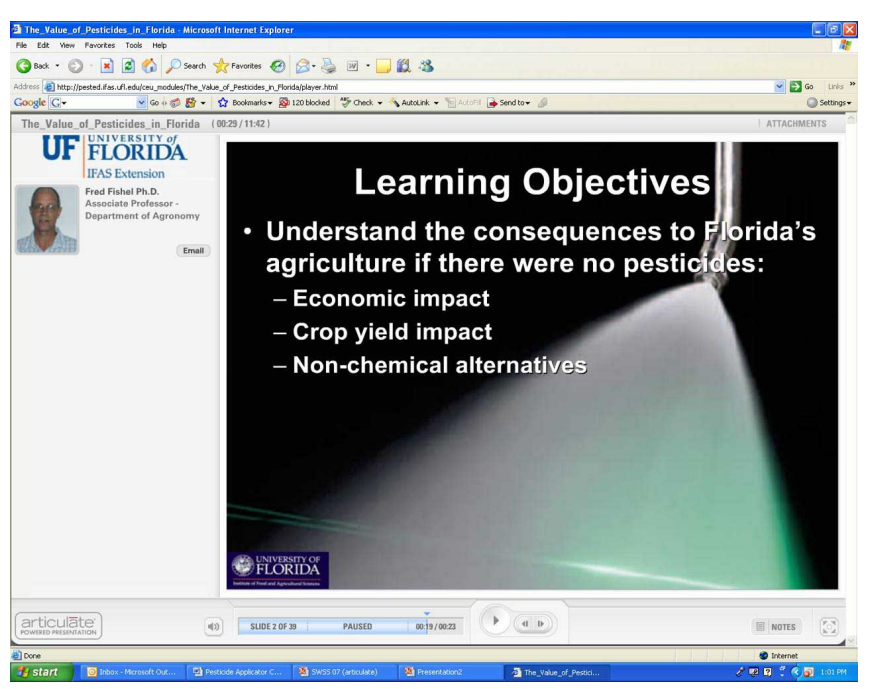

Figure 3. Example of tutorial learning objectives.

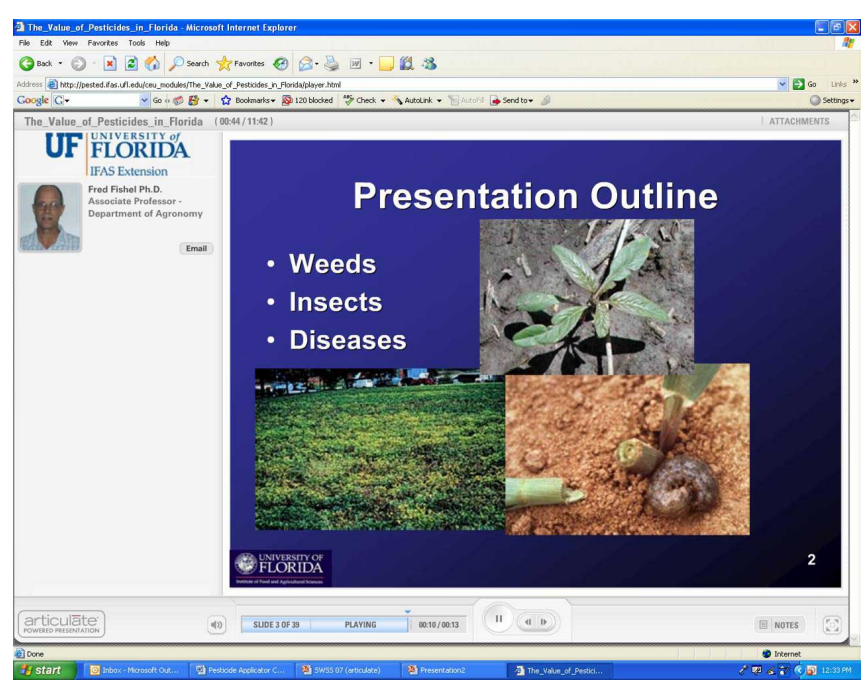

Figure 4. Example of tutorial presentation outline.

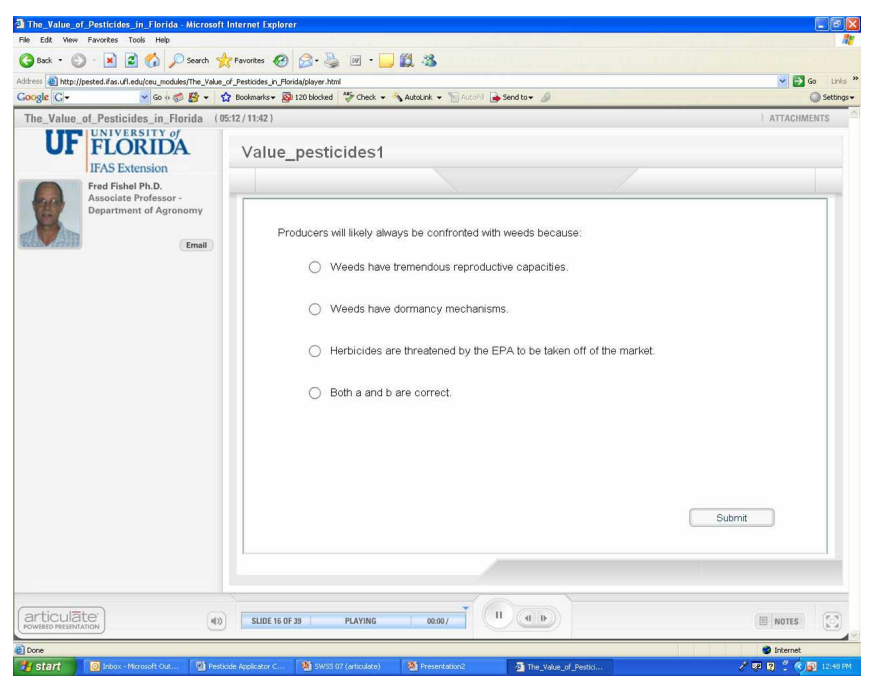

Figure 5. Example of tutorial quiz page.

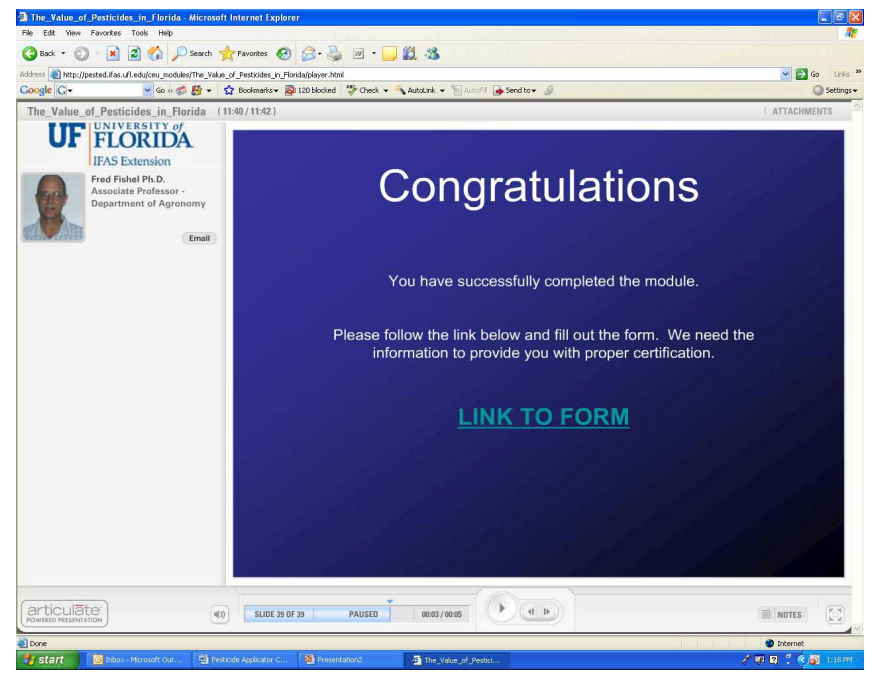

Figure 6. Example of tutorial successful completion page.

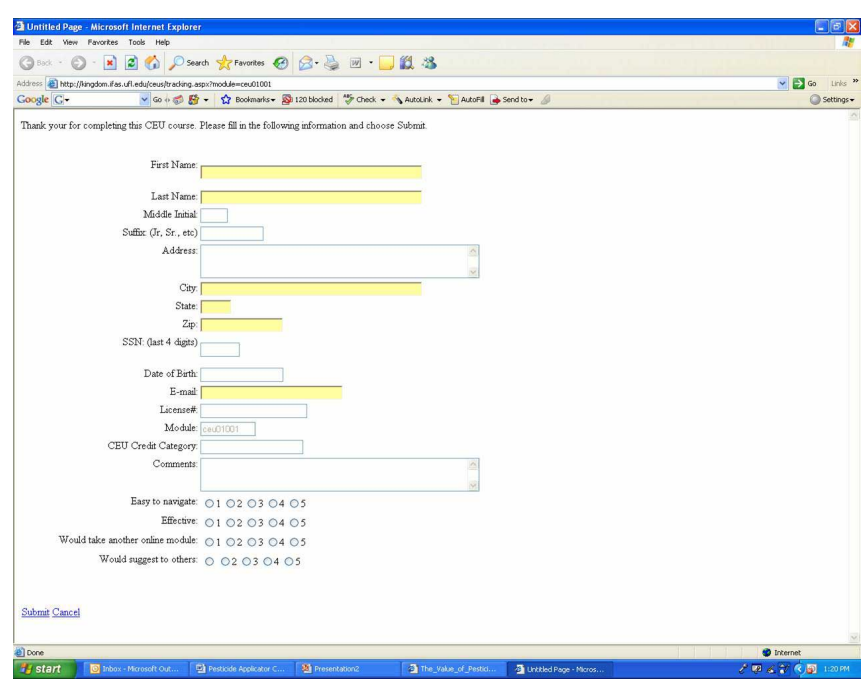

Figure 7. Example of tutorial user-required completion survey.

\section{Acknowledgements}

We gratefully thank the Florida Department of Agriculture and Consumer Services for partial funding support of this project and the cooperation of the IFAS Extension Bookstore.

\section{Additional Information}

Fishel, F.M. 2005. Agricultural and Related Pest Control Applicator License Classifications under the Florida Department of Agriculture and Consumer Services. UF/IFAS EDIS Document PI-59. http://edis.ifas.ufl.edu/PI095.

Langeland, K.A. 2004. Survey Results from Restricted Use Pesticide Applicators Concerning Education Needs and Preferences. Aquatics: 26, $4: 14-22$. 